\title{
The Use of Bionics and Semantic Panel for a Product Development
}

\author{
Ângela M. Marx \\ PG Student, UFRGS/Brazil \\ amarx@producao.ufrgs.br
}

\author{
Ronise F. Santos \\ Researcher, UFRGS/Brazil \\ ronises@producao.ufrgs.br
}

\begin{abstract}
The essence of the designers work is the creation of new solutions, usually related to the project of products to be produced in large scale. Thus, design is explicit in manufacturing companies but it is not usually related to raw material industries. However, designers work is necessary to materialize intangible products, as chemicals inputs, into concrete concepts. This is not as easy as it could seem and may demands special methods, as semantic panel. The semantic panel is a technique based on communication through metaphors. This can stimulate creativity allowing the designer to combine things that belong to different contexts and formulate new solutions to project from these associations. This paper describes the method and the steps performed for the development of a product that aims to turn tangible a new chemical solution with low environmental impact developed by an Italian chemical company. The method was conducted in two steps. First, an analysis of the design problem was performed by the designer and the company's technicians and executives. Secondly, a semantic panel was constructed under the theoretical basis of bionics to define practical, symbolic, aesthetic and green product functions. The bionic analysis of a groundling plant resulted in the detection of parameters that could be suitable for the product design, as a good balance, physical and mechanical strength. The concept, plus the problem presented and the semantic panel led to the requirements of the product aesthetics (color and texture), symbolism (meaning) and ecological factors (processes of tanning the leather with chemical inputs). The resulting product from this procedure; a purse, achieved the project goals expressing clearly the performance expected from the chemical input.
\end{abstract}

\section{Introduction}

The world is looking for quality and low prices solutions capable of meeting costumers' needs without compromising the environment [1][2]. To supply this demand on green products and services, it is necessary not only to create better products and components, but also to create better industrial inputs. This role is played by the chemical industry, historically responsible for the spreading of toxic substances in the environment [3].

The concept of green chemistry is approaching the chemical industry to Industrial Ecology ideas by the adoption of innovative techniques able to minimize the impacts caused by certain processes. The scope of these techniques is not limited to end-of-pipe solutions but it is linked to the pollution prevention or to processes of cleaner production. For such reasons, an Italian chemical company developed an innovative tanning input that could reduce the environmental impact of tanneries, responsible for the high environmental impact of leather products.

Although the investment in technology holds true, it became necessary to materialize the benefits of this new product for the company's clients. However, in order to do that, the company invested in design to create a product that translates all the input characteristics. This paper aims to present a design method based on semantic panel, bionics and reverse engineering used to create a product to turn this chemical solution tangible.

The semantic panel is a technique based on communication through metaphors. Metaphors can be defined as an expression of figurative language; the interpretation of an action or an object through the comparison to another object, action or symbol [4]. The use of metaphors can stimulate the biassociative thinking in a project, in which the designer associates different context elements and formulates new project solutions based on these associations [5].

Metaphorical techniques are used with different purposes. The semantic panel method, for example, is used in publications specialized in fashion, furniture and interior design to illustrate tendencies and guide the designers [6] [7]. The use of semantic panel is 
especially effective in these design areas that use ephemeral information to product development. Semantic panel can be applied in different new product development phases as in opportunities identification and in concept design, what makes it an important tool to optimize the product development management and the product competitiveness [8].

In a semantic panel, images are chosen for their meaning and are organized in the form of a panel of dimensions that can vary with the phase of the project, with the scope of product, the availability of staff and the need for scrolling, among other reasons. The images assembly is made to represent a guideline for the development design. It is important that the built visual environment is not static to be continuously updated along the product development process. This also makes the panel a continuous check list for the project goals [8].

Bionics [9] [10], also known as bio-inspiration [11] or biomimetic [9], is a theory constituted of methods of observation, comparison and analysis of the evolutionary solutions created by nature. It is based on the idea that natural systems created over the species evolution are the best solutions for many design problems. Thus, the main idea is not to imitate nature but to find the principles she uses [12].

The Bionics application passes through the observation of some natural system functions, its physical, chemical and biological properties. After, is necessary to draw the observed as a 2D or 3D model. Finally, the final project requirements are defined as well as its practical and aesthetical functions [12].

The use of traditional product design methods in this case could not provide the necessary support for creation of a product as innovative as the chemical input it represents. It is common to find cases of product development that start with diachronic and synchronic analysis, in fact a practice that inhibits the proposition of innovative solutions.

In fact, the designers' rejection to the use of unusual design methods is a behavior that exposes their limitation in realizing their real role to society, in the creation of better products, services and systems, mainly when the subject is environmentally-friendly products [13]. Design is not a trade or service for enterprises but a creative activity concerning products, services and systems conceived in industrialization logic [14] with an aesthetical component [15].

\section{Design method}

This study was conducted in two steps, in order to solve the problem using the semantic panel method and the fundamentals of bionics for the conceptual design. These steps and the correspondent results are described as follow.

\subsection{Step 1: Problem Analysis}

The first step is dedicated to the problem clarification and analysis. The activities concerned to this step are described in the sequence.

\subsubsection{Design Problem}

The problem was to design an artifact made with leather processed with a company's innovative chemical solution. The benefits of this new chemical input are the low environmental impact, the elevated productivity and the high quality. The artifact should communicate the input benefits through its concept. The intention was to exhibit the artifact in international commercial fairs and, after, in the company's showroom.

This is an unusual project, because it is necessary to cross the whole production chain to gather information to begin the development process.

\subsubsection{Design Problem Verification}

Some definitions and responsibilities must be defined before the beginning of the project. For this reason, a meeting with the company's project manager, the team project and the designer must be performed. This is important to guarantee the product alignment with the project objectives and to insert the project in a schedule. The definitions from the meeting are presented as follow:

a) The product must represent the essence of new chemical solution for vegetable tanning: softness, versatility for surface finishing and mainly the reduction of environmental impacts in the tanning process with the use of this input. The major challenge of this project is to change the current perception about vegetable tanned leather: a hard, low strength and low resistance to heat and little finishing versatility;

b) The leather development (tanning and finishing) must be performed by the company’s technicians from the project requirements defined by the designer;

c) The product must be manufactured by an atelier recommended by the designer;

d) The designer will be responsible for the product exposition and for the conceptual details of the fair stand. 


\subsection{Step 2: Product Design}

The second step comprehends the semantic panel building, the description of the concept through bionics and the product prototyping. These activities are described below.

\subsubsection{The Semantic Panel Construction}

The semantic panel technique is applied to design thinking and can be used individually or preferentially in groups. In this case, it was performed in group, with the team project under the coordination of the designer. It consisted of five phases:

a) The understanding of the design problem, what was achieved through a brainstorming;

b) The transformation of the verbal problem understanding in written language;

c) The processing of written language into visual through the search for images that really identify or translate the words listed or needs to be attended from the project objectives. The images used in this specific case were cut from magazines and gathered in the internet;

d) With the images in hand, team project performed the assembly of the visual environment, constructed by the panel composition,

e) After the panel composition, the colors palette, shapes and textures to be used in the product were defined.

As an additional step, a small text was inserted to describe the panel, to facilitate the team project understanding. The resulting semantic panel is represented in Figure 1. This panel describes visually the essence of the design problem defined by keywords in the brainstorming: vegetable, healthy, flexible, natural, dynamic, performative, evolving and transformative.

\subsubsection{Bionics Application}

The semantic panel constructed was used as a guide for the designer. The observation of the groundling plant defined the following product characteristics: resistance, portability, junction, mobility and balance. From this observation, some possibilities were draw as demonstrated in Figure 2.

Taking similarity into account, these sketches defined the artifact to be developed: a purse. This solution was also sketched, what can be observed in Figure2.

Beyond the artifact definition, the groundling plant study defined some characteristics, as movements' balance, shape, colors and surface textures. These characteristics are the properties of the materials that should be used in the purse composition.

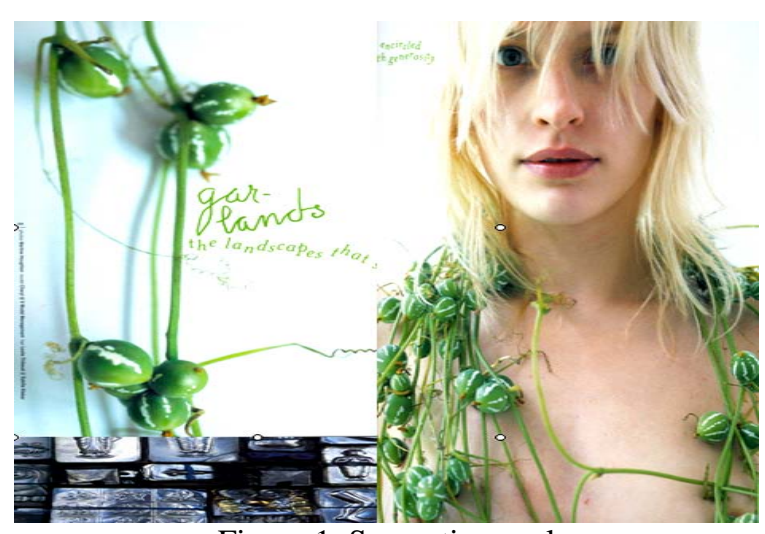

Figure 1. Semantic panel

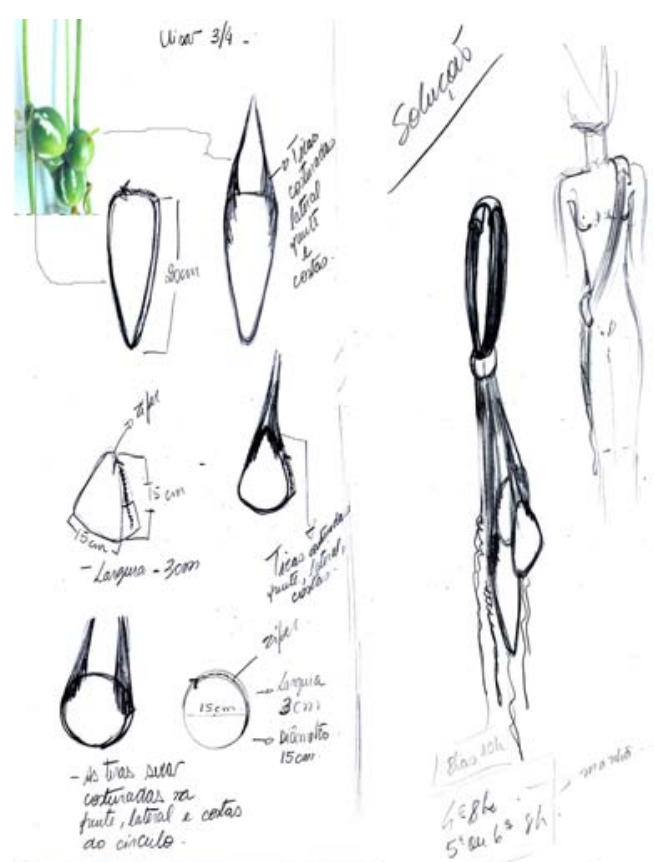

Figure 2. The groundling plant study

\subsubsection{Product Prototype}

The purse prototyping was realized in two moments. The semantic panel (Figure 3), incorporated with the Bionics concepts, was used to guide both company's technicians and the atelier professionals during the prototyping.

First, the leather component was developed according to the characteristics defined in the Bionics study: flexibility, natural finishing, colored with 
natural green pigments and vegetable tanning. This development was carried out by the company's technicians in its own facilities.
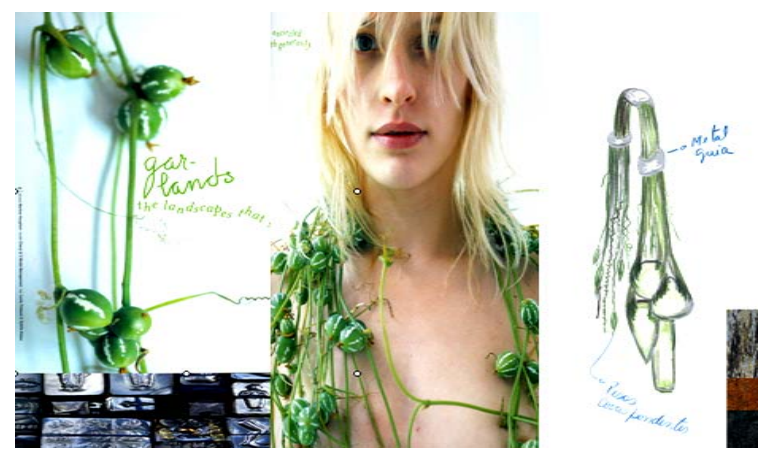

Figure 3. The semantic panel after the Bionics study

Secondly, the purse prototype was manufactured in a professional atelier. This product caused a great change in the atelier technicians working method. These professionals are used to prototype artifacts based on existent products and the confection of an innovative purse was a great challenge.

\section{Results and discussion}

The solution for the design problem was a plant purse, as it was called by the atelier's professionals. This fact suggests that the project was successful in its direct symbolic communication.

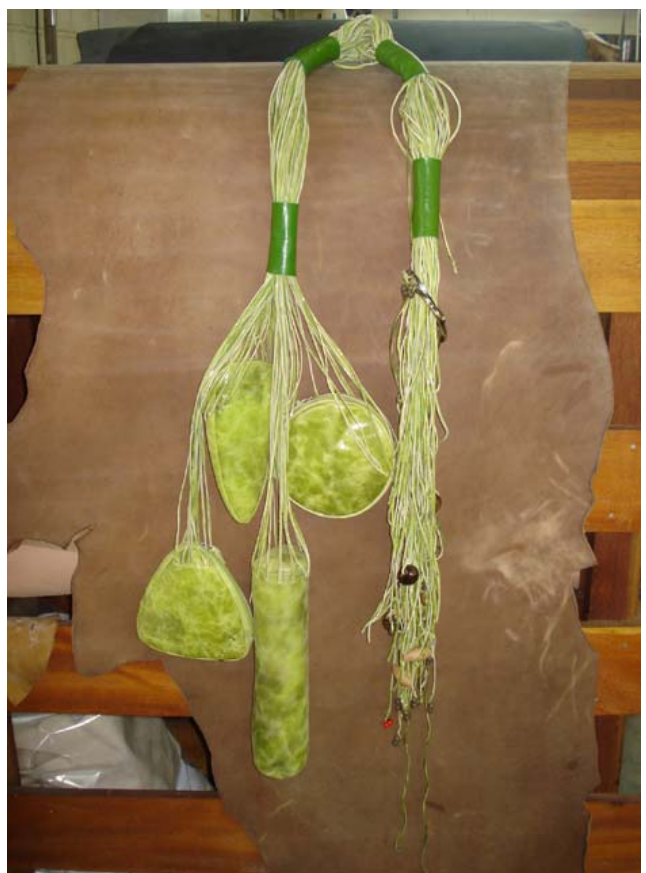

Figure 4. The purse: solution for the design problem
The aesthetical function was directed to the different ways of using it. Beyond the natural symbolic appeal, the purse can be dressed as a lace or an écharpe, promoting a stile differentiation. The Figures 5 and 6 .present different ways of use the purse.

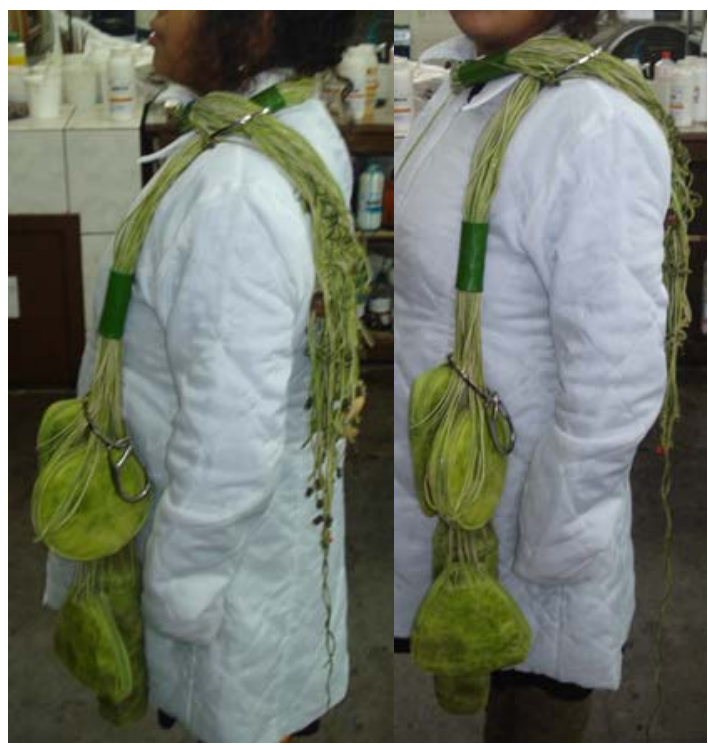

Figure 5. The purse dressed as an écharpe

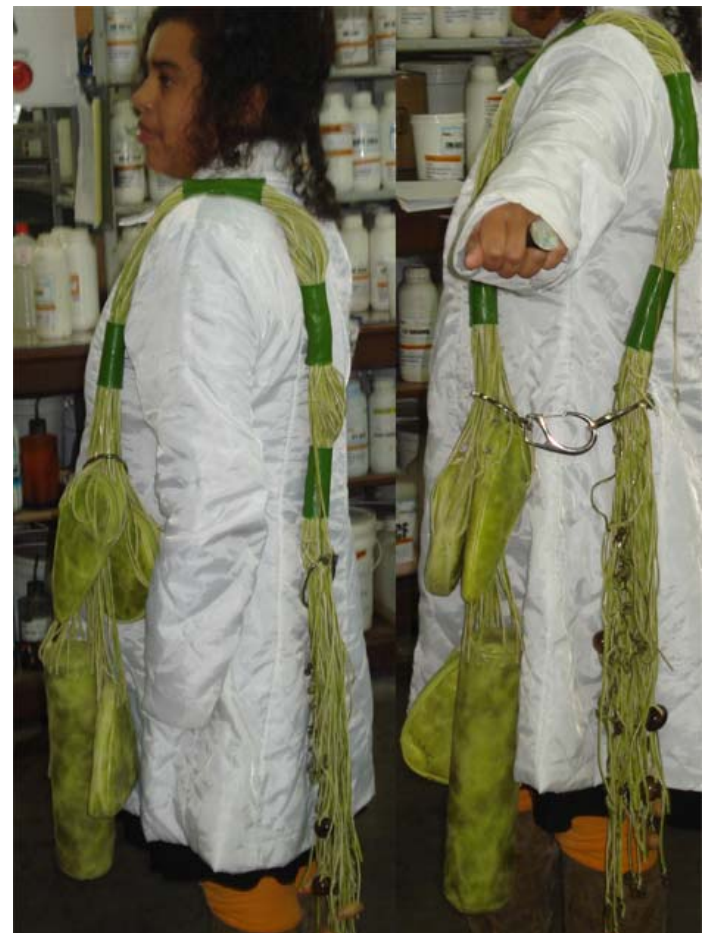

Figure 6. The purse used as a pendulum (in the left) and its common use (in the right) 
The purse handle was composed by many wires made in wired leather, without lateral finishing, what can be visualized in Figure 7. This way of cutting allows the identification of the tanning process used, turning easier the work of fair costumers.

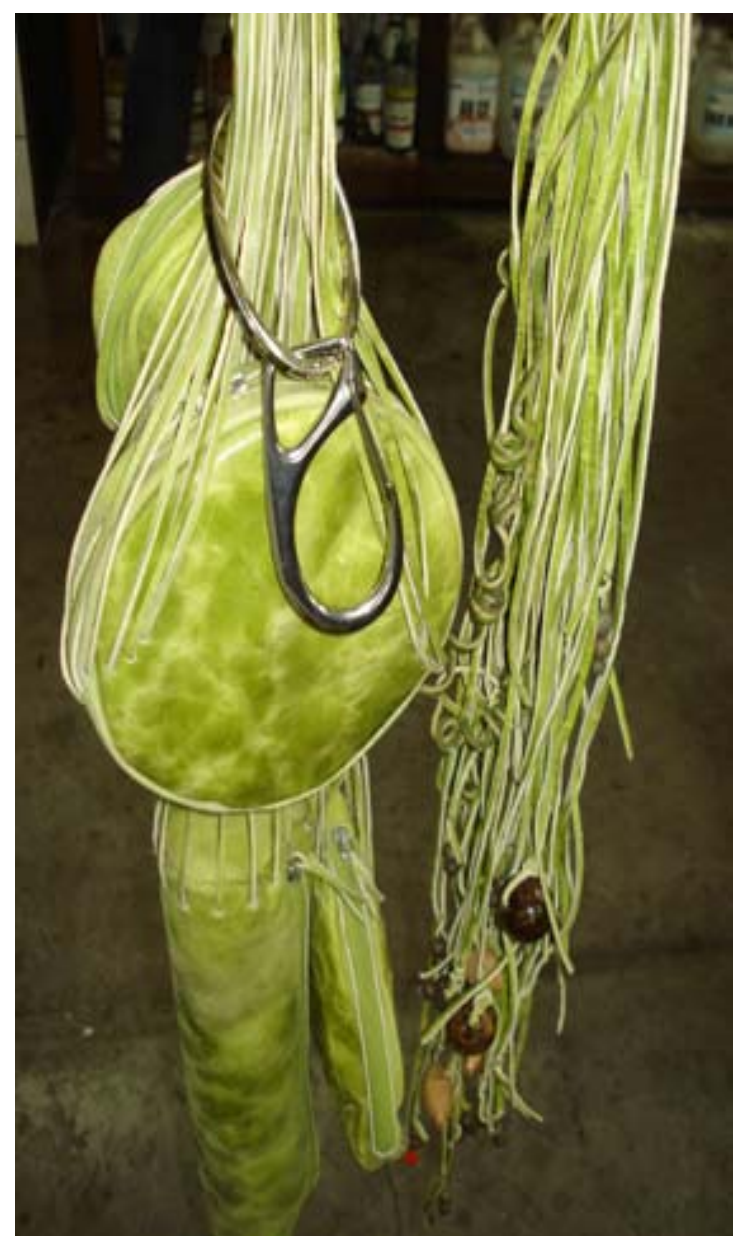

Figure 7. Detail of the purse handle

The stand project followed the same theories that guided the product concept development, considering the environment. Its aesthetics was defined by earth colors and organic shapes with the semantic panel exposed on the stand walls.

\section{Conclusions}

Our proposition was to present the method used for the development of a purse that could materialize a chemical input for vegetable tanning using semantic panel and bionics. We believe that this work can contribute for the design field, presenting the development of an environmentally-friendly product from a different approach.

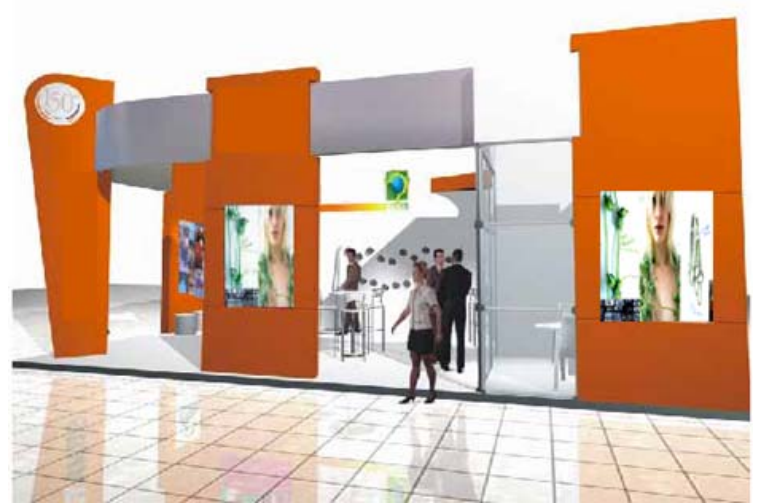

Figure 8. The stand project

Although this paper has reached its aims, it has other contributions. The demand of a more sustainable product from a chemical company is unusual and it turns evident the interdependence of the leather chain from these supply companies. The creation of an ecological product depended on effort to find low impact inputs and processes, as a vegetable tanning process and the natural pigments used in this case.

In this particular case, the product that was designed is not the company's final product but a marketing piece. The similarity with the product made by the costumer's companies was necessary to show the chemical solution properties to its target market.

This is an unusual project that shows the necessity of understanding the whole production chain needs to create a final solution for both clients and the environment.

\section{Acknowledgments}

We would like to thanks the company's technicians, especially Simoni Solunto, who developed the leather.

\section{References}

[1] L.B.M.Guimarães, Design Sociotécnico, PPGEP, UFRGS, Porto Alegre, 2008.

[2] L.B.M.Guimarães, “ Projeto Fábrica da Inclusão”. Conselho Nacional de Pesquisa: no. 507245/2004-0. Edital CNPq 014/2004, 2004.

[3] C. M.V.B. Almeida and B. F. Gianneti, "A Indústria Química no Contexto da Ecologia Industrial”, Revista de Graduação da Engenharia Química, Ano VI, no. 12, LaFTA, Universidade Paulista, São Paulo, Brasil, Jul-Dez 2003. 
[4] J. Hey, J. Linsey, A.M. Agogino and K.L. Wood, "Analogies and Metaphors in Creative Design", International Journal of Engineering, University of California, Berkeley, 2008, Vol. 24, No. 2, pp. 283 294 .

[5] M. Baxter, Projeto de Produto, guia prático para o desenvolvimento de novos produtos. Edgard Blücher, São Paulo, 2006

[6] PANTONE. Pantone View Color Planner Summer 2010. INC PANTONE:Pantone Color System, United States, 2009, pp. 92.

[7] WGSN. "The Global leader for style trend analysis", Available at <http://www.wgsn.com/home> 15/june/2009.

[8] R.F.SANTOS and J. JACQUES, “O Painel Semântico como Ferramenta no Desenvolvimento de Produtos (The Semantic Panel as a Product Development Tool)", Proceeding of the $5^{\text {th }}$. International Congress of Design Research, UNESP, 2009, pp. 1-8.

[9] B.L. Zhou, "Bio-inspired study of structural materials", Materials Science and Engineering, Elsevier, 2000, pp. 1318.
[10] S. Schäfer, "Bionic for Building Industry", Darmstadt Concrete. Available at $<$ http://www.

darmstadt-concrete.de/2003/bionics.html>, 23/may/2003.

[11] H. Wen, S. Zhang, K. Hapeshi and X. Wang. “An Innovative Methodology of product Design from Nature", Journal of Bionic Engineering,

http://www.sciencedirect.com, 2008, pp. 75-84.

[13] E. Manzini and C. Vezzoli, O Desenvolvimento de Produtos Sustentáveis (Lo sviluppo di prodotti sostenibili: I requisiti ambientali dei prodotti industriali), EDUSP, São Paulo, Brazil, 2005.

[14] International Council of Societies of Industrial Design(ICSID), "Definition of Design”, Available at: $<$ http://www.icsid.org/about/about/articles31.htm?query_pag $\mathrm{e}=1>$, 20/june/2009.

[15] G. Dörfles, Introdução ao Desenho Industrial. São Paulo: Edições 70, 1972. 